\title{
Catedral Metropolitana de Campinas: quando um edifício contempla a história
} da cidade.

Paula Marques Braga* e Maria Cristina Schicchi**

\section{Resumo}

O trabalho tem por objetivo refletir sobre a preservação do patrimônio cultural a partir de um edifício representativo da cidade de Campinas, a Catedral Metropolitana.

A partir de um histórico sobre o edifício e de uma síntese das intervenções de restauração e reabilitação nele realizadas, com o fim de definir seu papel no programa maior de reabilitação do centro histórico, em curso na cidade, busca-se discutir os desafios da preservação em áreas de grande dinâmica urbana, como Campinas.

Palavras-chave: Patrimônio. Restauração. Reabilitação.

\section{Campinas Metropolitan Cathedral: when one building represents the history of} the city.

\begin{abstract}
The research has for objective to understand the question of the historic site from the study of a representative building of the city of Campinas, the Metropolitan Cathedral.

From both the building historic and the restoration and rehabilitation interventions synthesis, to define the building paper in the rehabilitation program in course in the historical center, one searchs to argue the challenges of the preservation in areas of great urban dynamics, as Campinas.
\end{abstract}

Key words: Heritage. Restoration. Rehabilitation. 
Está em curso hoje, na cidade de Campinas, o inventário arquitetônico e urbanístico de sua área central (1), um projeto adiado inúmeras vezes nos últimos dez anos. Não obstante, parece oportuno que isto tenha se dado tardiamente uma vez que hoje é possível um olhar ampliado sobre o patrimônio construído dos centros urbanos, o que permite esperar que este levantamento venha a constituir mais do que o registro de edifícios "históricos", e detecte onde se localizam aqueles imóveis representativos de sua história, arquitetura e desenvolvimento urbano simultaneamente.

Identificar as áreas que concentram maior número de imóveis e definam conjuntos arquitetônicos significativos será a maneira utilizada para resgatar a história e a arquitetura desta cidade, uma vez que Campinas, ao longo do último quarto do século passado, perdeu quase todo o seu conjunto construído de maior expressão. Restaram as edificações isoladas como o Palácio dos Azulejos, o edifício da Mogiana, o da PUC Central, a Escola Carlos Gomes, o Mercado Municipal e outros todos eles referenciais em suas áreas envoltórias - como o conjunto de edifícios do patrimônio ferroviário e industrial das Companhias Paulista e Mogiana.

No entanto, um edifício patrimonial, a Catedral Metropolitana (tombada pelo Condephaat (2), em 1981, e pelo Condepacc (3), em 1988), se destaca dentre todos, não só por sua precedência e importância na história da cidade, mas também por se constituir em marco permanente na construção e reconstrução do traçado urbano de seu centro histórico, ao longo do tempo. 


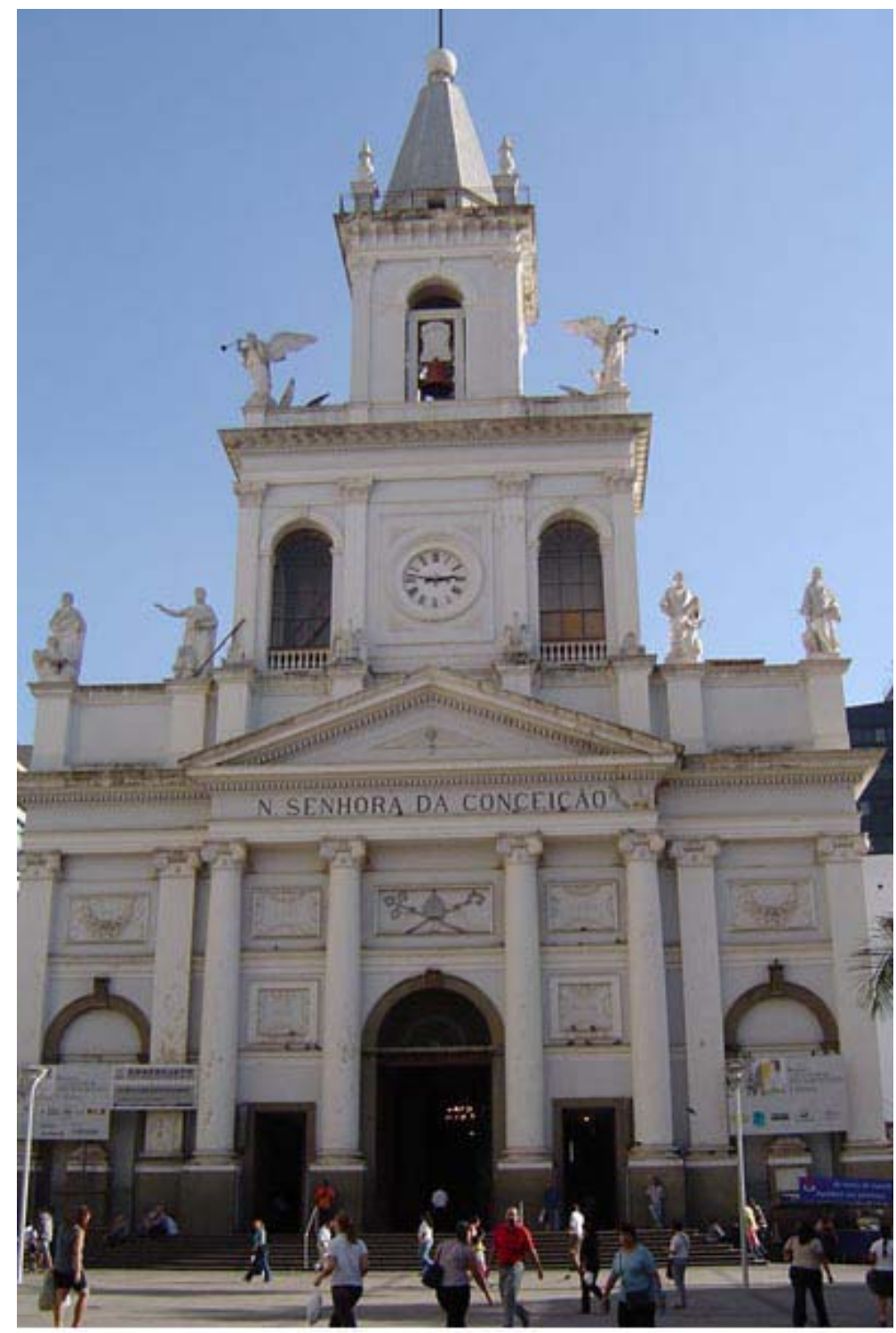

FIGURA 01 - Catedral Metropolitana de Campinas. Fotografia: Paula Marques Braga.

O Projeto Centro, um programa de reabilitação do Centro Histórico, que inclui a criação de organismos e intervenções em edifícios e áreas (4) tem como ponto principal a obra de restauro em curso na Catedral Metropolitana. Essa escolha se justifica por ser a Catedral seu maior monumento ainda em uso, localizada no ponto principal de comércio da cidade, na Praça José Bonifácio, junto à Avenida Francisco Glicério (grande circulação de veículos) e a Rua 13 de Maio (maior via de circulação de pedestres). 


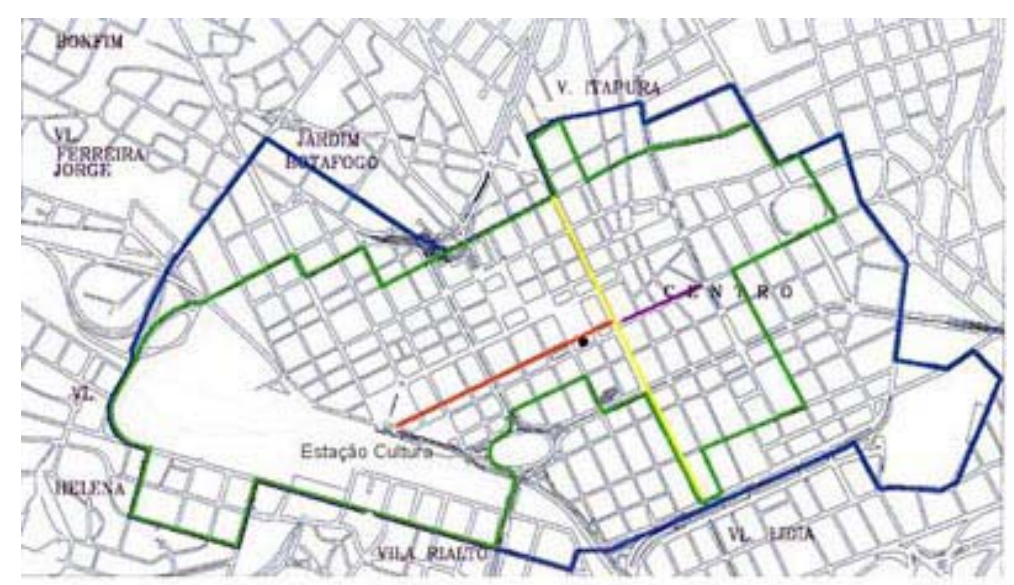

FIGURA 02 - Desenho: Paula Marques Braga.

A identificação entre o edifício da Catedral e o Centro de Campinas é inevitável, posto que o estudo de sua localização revela a mudança de condição geográfica do centro e, mais tarde, irradia as direções de crescimento da cidade.

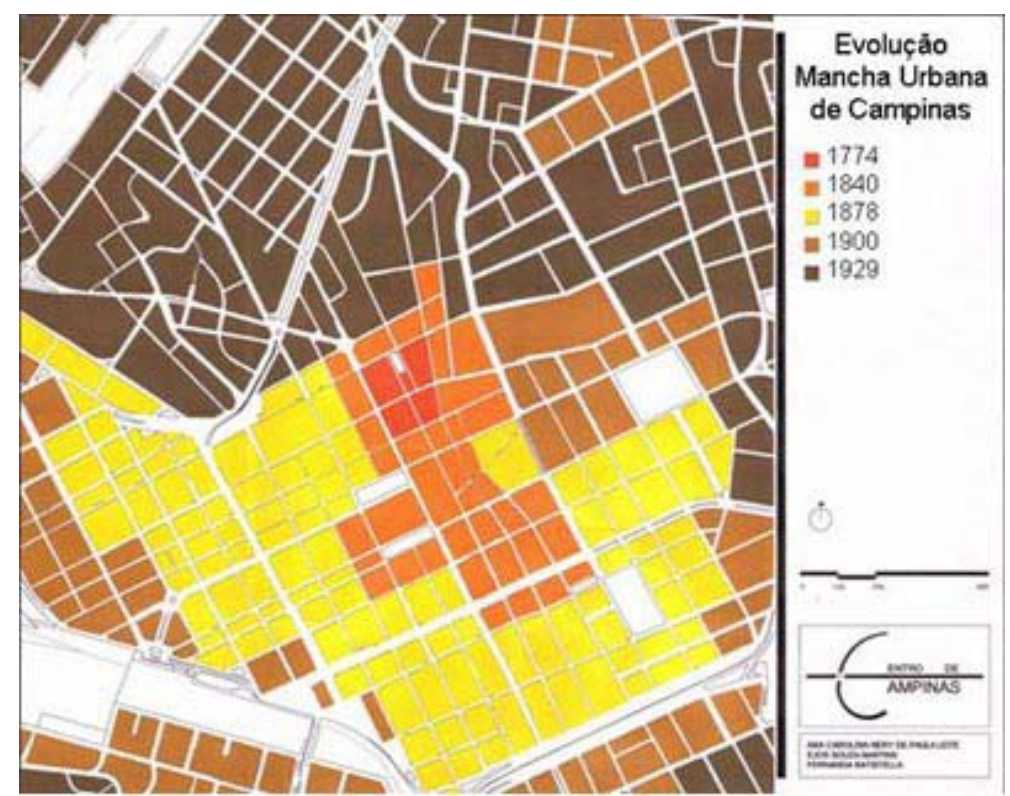

FIGURA 03 - Mapa: Ana Carolina N. de P. Leite, Ejos S. Martins e Fernanda Batistella. Trabalho Final de Graduação, PUC-Campinas, 2003.

A decisão de se construir uma Catedral para Campinas foi tomada no ano de 1807, quando o templo da então Vila de São Carlos se tornara pequeno para o número de fiéis, e sua construção teve início em 1808.

O sítio, terreno do rocio para a nova construção, já havia sido escolhido e obtida a licença para edificar. O local era uma área ainda em mata, fora do perímetro urbano da Vila, o que já indicava a previsão de seu crescimento (5). 
O arruamento que configura a área central de Campinas manteve-se o mesmo, desde sua constituição entre os séculos XVIII e XIX, até a segunda década do século $X X$, quando a abertura de ruas e a formação de bairros começaram com os loteamentos das fazendas de café. Com a construção da Matriz Nova, a Catedral Metropolitana, surgia um novo espaço, e com ele um novo centro, compatível com o crescimento da Vila, distanciando as práticas religiosas das atribulações da Cadeia Provisória e do Pelourinho, que se encontravam junto à então Matriz Velha, no Largo do Carmo (BADARÓ, 2002).

Tendo sido sua construção idealizada pelos "barões do café", e tendo eles suas casas na cidade naquela região, o que se pode inferir é que a construção do edifício se deu muito mais por interesse desta elite do que como expressão do desenvolvimento da cidade. Na época em que foi idealizada, era muito comum se expressar relações de poder através de símbolos de ostentação, e ter uma Catedral imponente dava à cidade tal condição.

Sua inauguração deu-se em 8 de dezembro de 1883. Quando inaugurada, não tinha a configuração de hoje. Sua construção foi realizada em etapas, e não há documentação disponível a respeito do primeiro projeto e de sua construção. Em relação à intenção original do projeto, o que se tem registro é que seriam construídas duas torres na fachada principal. Esta idéia foi abandonada devido à falta de técnica disponível na época para a sua sustentação, decidindo-se por apenas uma, no centro. As mudanças posteriores realizadas na Catedral ficam evidentes nas intervenções realizadas em 1923 e 1952.

A conclusão da Catedral, a partir de 1880, foi obra de Ramos de Azevedo, que, ao chegar para assumir a direção das obras, produziu um relatório a respeito do andamento dos trabalhos, descrevendo a situação em que se encontrava (6). A atuação do arquiteto nessa obra foi fundamental para sua carreira profissional, projetando o seu nome para todo o país.

O crescimento da cidade e a configuração de sua área central só vieram a reforçar a localização privilegiada da Catedral Metropolitana no centro de Campinas, e isto se torna evidente se compararmos os mapas de evolução do centro. (7) 
Entretanto, esse mesmo crescimento marcou a mudança de paisagem na qual se insere a Catedral. Com a crise da economia cafeeira na década de 1930, a cidade "agrária" de Campinas assumiu uma fisionomia mais industrial e de serviços.

A cidade recebeu, em 1938, um plano urbanístico denominado "Plano Prestes Maia", que reunia um grande conjunto de ações voltadas a reordenar suas vocações urbanas e impulsionar velhos e novos usos, como o de pólo tecnológico do interior do Estado de São Paulo. O plano mudou a fisionomia da cidade, uma transformação profunda em relação à cidade anterior do café.

Como parte do Plano, a configuração urbana do entorno da Catedral foi modificada, sendo alargado o trecho inicial da Rua Conceição, em frente a ela.

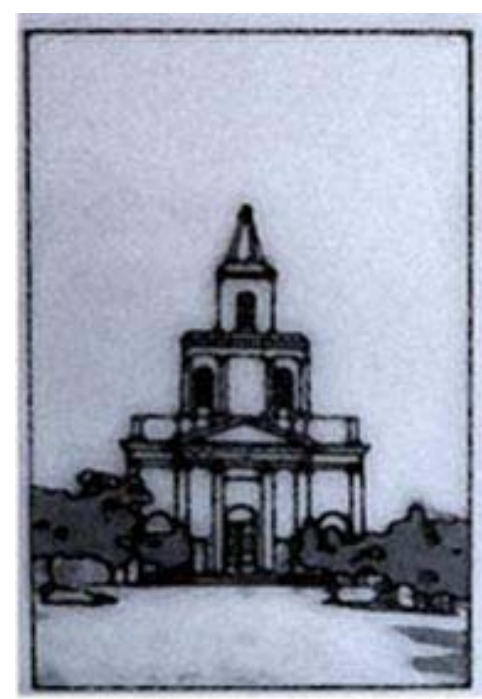

1900

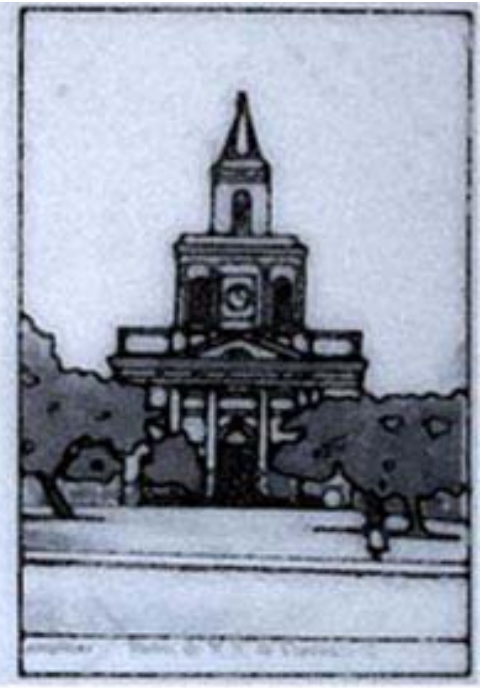

1905

FIGURA 04 - Desenho interpretativo das fotos de época.

Nฮ̃o há ainda o arruamento definido. 


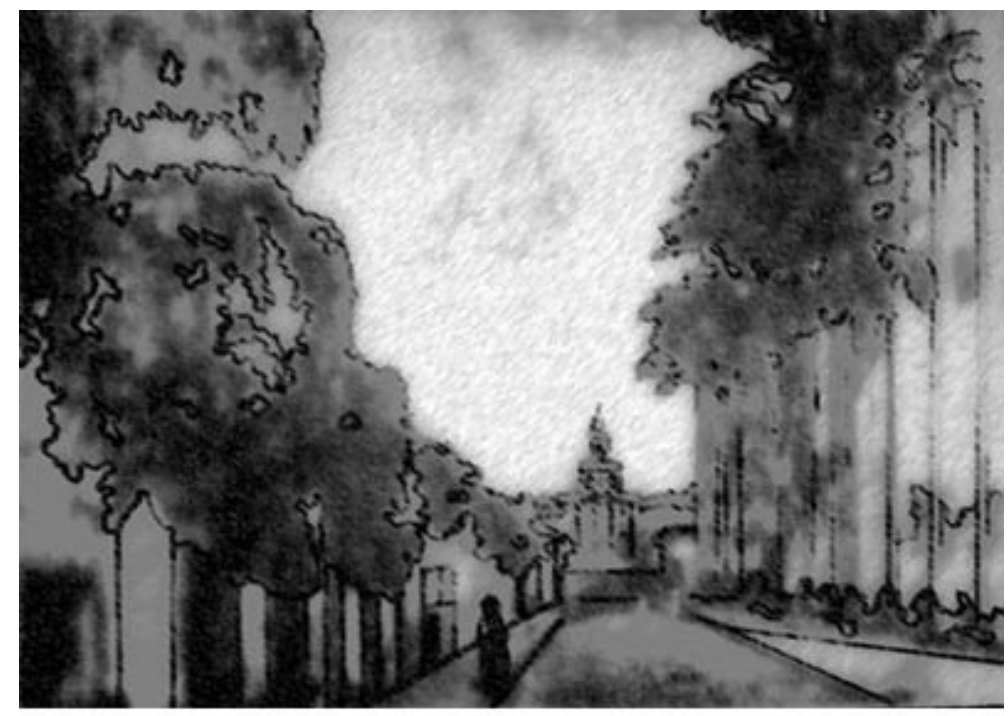

FIGURA 05 - Rua Conceição, quando ainda se chamava Rua Formosa, em 1910. Desenho interpretativo das fotos de época.

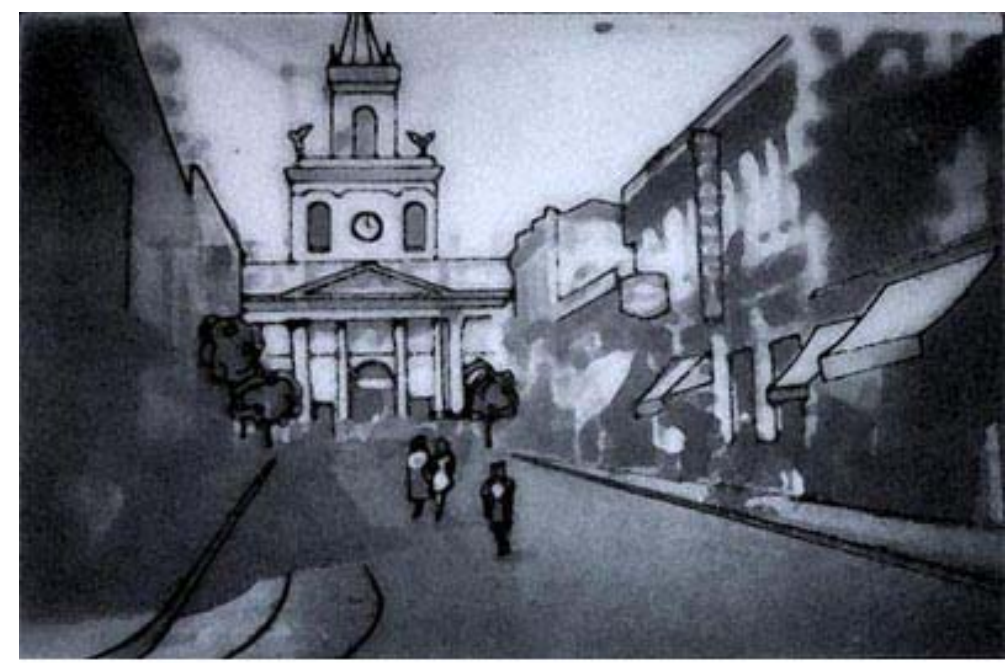

FIGURA 06 - Rua Conceição, em 1942. Desenho interpretativo das fotos de época.

Através de imagens da Catedral, podemos perceber a evolução do próprio centro, que modificou sua relação com o entorno e envolveu-a em meio a uma massa verticalizada que a fez desaparecer, de forma que hoje preservar somente a tipologia arquitetônica não garante mais a feição paisagística urbana (SESSO JÚNIOR, 1970).

Por outro lado, a questão de sua localização nos ajuda a entender porque a fachada frontal da Catedral foi, desde o início, motivo de preocupação, o elemento mais importante em quase em todas as intervenções que o edifício sofreu. A fachada era não só o elemento que identificava este "epicentro" à distância durante muito tempo, principalmente por se localizar no eixo que culmina com a entrada/saída da Estação 
Central, mas era também por onde se recebia o visitante, tendo sido, ao longo do tempo, o aspecto mais polêmico de sua obra.

A questão da construção da fachada é um aspecto interessante para o entendimento da transformação do centro da cidade e do valor da imagem de um edifício em si na preservação de sua identidade.

Devido ao longo período de construção, seu estilo arquitetônico não corresponde à intenção original e não apresenta relação com o estilo interior da obra. Tal constatação serviu de argumento para que o pedido de tombamento contemplasse apenas o interior do templo.

O primeiro relatório de tombamento apresentado ao Condephaat sugeria o tombamento apenas do interior do templo, considerado mais resolvido que o exterior. Porém esta decisão não foi aceita (8) e os elementos reconsiderados para o tombamento foram:

1. Harmonia do interior;

2. Significativos trabalhos de entalhe;

3. Grandiosidade do conjunto de taipa, considerada monumental para uma cidade do porte de Campinas no século XIX;

4. Significado local da sua construção;

5. Marco histórico e religioso que representa.

“... Os desvios, as irregularidades, os defeitos de simetria são fatos históricos repletos de interesse, os quais freqüentemente fornecem os critérios arqueológicos para confrontar uma época, uma escola, uma idéia simbólica.” (BOITO, 2003, p. 60)

Ou seja, ficou estabelecido que mesmo não apresentando uma identidade de estilo e forma, representava no seu conjunto um autêntico documento de sua história, embora tenha sofrido diversas interferências ao longo dos 76 anos de construção. Com esta ressalva, a Catedral foi tombada em todo o seu conjunto.(8)

Hoje, a Catedral é conhecida e reconhecida por ambos os aspectos, seu interior e sua fachada frontal atual, que se sobrepôs a todas as anteriores. Curiosamente, sua 
implantação conforma uma quadra independente, possuindo na verdade duas fachadas, o que faz de sua construção um elemento de intermediação entre duas praças, marcando o lugar de forma singular, pois após a construção do calçadão da Rua 13 de Maio, o edifício passa a poder ser contemplado de todos os lados, e também a uma distância que permite apreendê-lo por inteiro. A área concentra o fluxo de 200.000 pessoas (9) que atravessam o centro diariamente, vindas dos terminais e de outros pontos de chegada ao centro, e o edifício é cruzado obrigatoriamente por quem passa por aquela região, tornando-se lugar de permanência através de suas escadarias.

Entre tantos edifícios patrimoniais que vão perdendo suas funções e restam esquecidos no centro da cidade, a Catedral se mantém ativa e é seu maior monumento em uso. Isto se deve em boa parte à permanência do programa original, não apenas o religioso, mas também às atividades sociais, entre elas as da Irmandade do Santíssimo - muito antiga - que financiou até mesmo parte da primeira reforma realizada no edifício. A Irmandade do Santíssimo foi criada em Campinas no início do século XIX e seu objetivo era manter "com todo o esplendor da Liturgia da Igreja Católica o culto de adoração do Santíssimo Sacramento da Eucaristia (...)" (LEITE, Ricardo, 2004)

A manutenção do uso, discutida em muitas "Cartas Patrimoniais" (IPHAN, 1995) como a forma de manter o edifício antigo vivo e conservado diante da dinâmica urbana das cidades, é o que garantiu a vitalidade da Catedral até os dias atuais. Além da realização das missas diariamente, possui outras atividades, como apresentações musicais e atividades de lazer e cultura, como o Museu de Arte Sacra que tem grande acervo e que, com o projeto de restauro em curso, terá seu roteiro de visitação ampliado.

Este projeto de restauro foi elaborado pelo L'Habitat, por alunos do Curso de Especialização em "Patrimônio Arquitetônico: Teoria e Projeto" da Puc-Campinas, coordenado pelo arquiteto Samuel Kruchin, em 1999. O projeto foi retomado e revisado por duas vezes, em 2001 e em 2003, quando foram atualizados os levantamentos das patologias apontadas na estrutura e nos revestimentos, através dos trabalhos do L'Habitat da PUC-Campinas, e do trabalho dos alunos das 
disciplinas do Curso de Especialização "Patrimônio Arquitetônico: Teoria e Projeto", neste caso, coordenado pela professora Maria Cristina Schicchi.(10)

O projeto de restauro teve início com pesquisa histórica para obtenção de dados importantes para o entendimento do edifício. Posteriormente foram realizados o levantamento da iconografia e o desenvolvimento da edificação, da data de construção aos dias atuais. Foram também realizados o levantamento métrico arquitetônico e o diagnóstico detalhado das patologias observáveis no edifício.

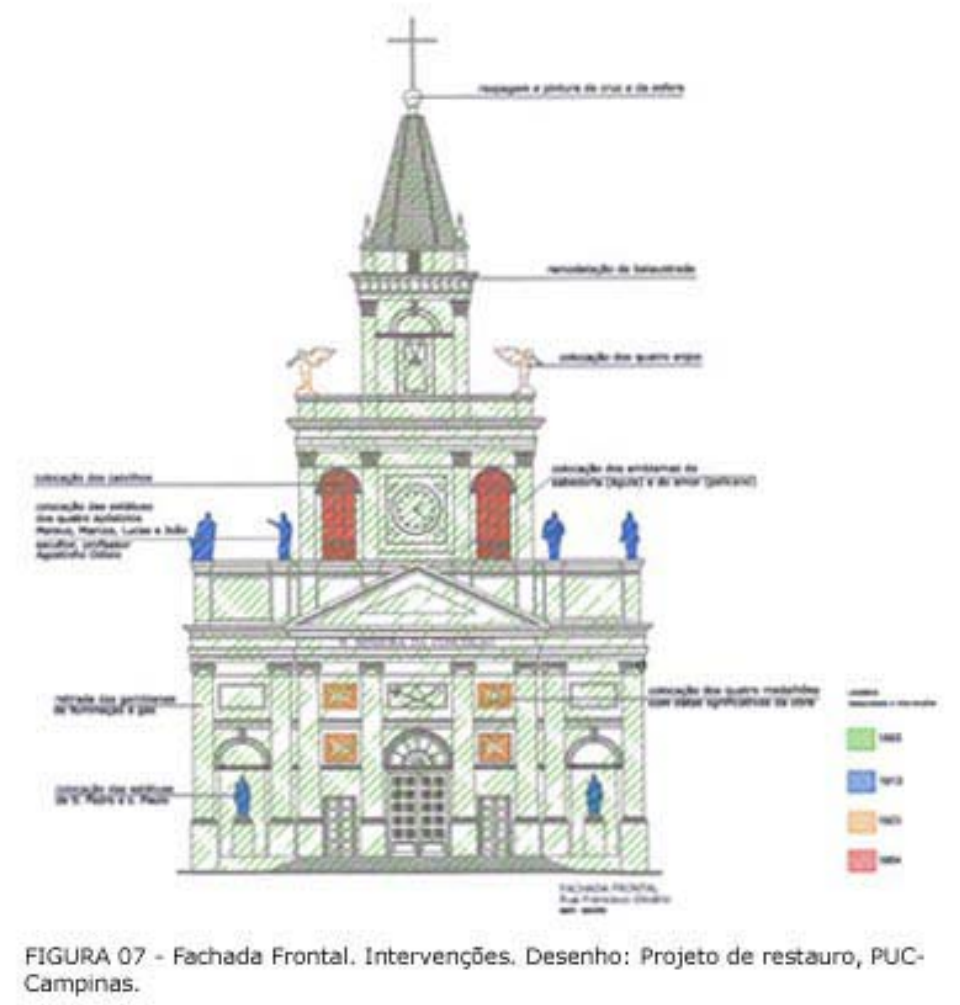

O projeto de restauração da Catedral foi enviado ao Ministério da Cultura e foi beneficiado pelos incentivos fiscais da Lei Rouanet. Pela lei, 4\% do Imposto de Renda das empresas podem ser destinados a projetos culturais aprovados, ou seja, a quantia que uma empresa destinar à restauração da Catedral poderá ser deduzida do valor a ser pago do IR.

O arquiteto Ricardo Leite foi o coordenador da obra pelo Grupo Gestor da Obras de Restauração da Catedral. Durante o início das obras de restauração, a PUCCampinas empreendeu, por solicitação da própria Catedral, e sob a coordenação da 
professora Maria Cristina Schicchi, o projeto para a criação do "Centro de Memória Catedral Metropolitana de Campinas", com a participação de várias faculdades da universidade, e da própria equipe técnica da Catedral em sua elaboração - um projeto multidisciplinar ainda em estudo.(11)

Para a realização das obras, que se iniciaram pelo forro, foi instalado um piso técnico a $21 \mathrm{~m}$ de altura, próximo ao teto da Catedral, para que as atividades no corpo principal do templo pudessem transcorrer normalmente.

A obra é a terceira intervenção pela qual o edifício passa. Quando inaugurada, a Catedral de Campinas não tinha a configuração que apresenta hoje, fato que podemos comprovar através das análises das intervenções sofridas pelo edifício, que evidenciam também algumas das mudanças de postura em relação ao conceito de restauração.

Na primeira reforma realizada no edifício da Catedral, em 1923, portanto, quarenta anos após a sua inauguração, as primeiras características foram em grande parte alteradas. O primeiro cuidado ao projetar esta obra foi desafogar o altar-mor através da elevação das paredes laterais da capela-mor ao mesmo nível das do corpo principal. Destacou-se ainda, como importante realização nessa ocasião, a grande cúpula de cimento encimada pela imagem da Virgem Maria, substituindo-se assim o pequeno zimbório de vidros coloridos então existente.

Os trabalhos de reforma abrangeram quase todo o edifício, que sofrera desgaste natural pela ação do tempo. A fachada principal apresentava sua estética prejudicada, pois, com as adaptações da antiga iluminação a gás, a pintura externa estava enegrecida. Internamente, foi realizada a construção da cripta de mármore abaixo da capela-mor. (12)

Nota-se obviamente que esse primeiro processo de intervenção realizado na Catedral, executado no ano de 1923, não se sujeitou a nenhum tipo de fiscalização, sendo, dentre todos, o processo que mais modificou o edifício. 
A segunda reforma, de 1952, foi comandada pelo engenheiro Lix da Cunha, sendo realizada a cobertura da cúpula com revestimento, fechamento da iluminação do zimbório, aterramento do porão com provável troca do tabuado de madeira da grande nave. (12)

A última intervenção realizada, ainda em curso, é a que mais se ateve às teorias de restauração. Apresenta bom registro da situação da edificação antes do início do processo de intervenção, com levantamentos fotográficos e descritivos dos principais problemas e de detalhes mais relevantes da obra. Uma das partes mais delicadas diz respeito à recuperação dos ornamentos em madeira, extremamente danificados por cupins, cujo processo de restauração se deu através da reconstituição das partes faltantes.

O projeto de restauração atual seguiu os preceitos da "Carta de Veneza Monumentos e Sítios", de 1964, realizando a elaboração de documentação, através de relatórios analíticos e críticos, ilustrados com desenhos e fotografias (IPHAN, 1995).

As "Cartas Patrimoniais", como já dissemos, ao tratarem do edifício antigo, ressaltam a importância de dar-lhe um uso adequado às necessidades da cidade contemporânea. O caso da Catedral de Campinas é emblemático, neste sentido. Tendo permanecido o uso religioso, sem transformações, a Catedral é o único monumento do centro da cidade de Campinas que se conserva "por" e "para" o uso original, enquanto todos os outros edifícios históricos passaram por algum processo de degradação e/ou abandono, sem investimentos públicos para sua conservação. Esta situação acarretou uma dificuldade em estabelecer usos mais perenes para esses edifícios e vice-versa, a efemeridade de novas funções atribuídas a esses edifícios, em geral, com adaptações de programas, sem levar em conta projetos específicos de reabilitação, acabou por reforçar o aspecto de subutilização em que se encontram.

Em outras palavras, embora a necessidade de discussão dos usos seja hoje um consenso para garantir vida ao patrimônio edificado, durante muitos anos as intervenções privilegiaram os usos excepcionais e complexos, como os de museus, 
centros culturais, e outros institucionais, decididos a priori, às vezes inadequados para a reabilitação dos edifícios, em detrimento de usos mais cotidianos e/ou de interesse coletivo da população.

O projeto de restauro da Catedral propõe a reformulação de seu espaço de exposições, organizando e criando um roteiro de visitação que inclui a própria Catedral como objeto de estudo e contemplação, criando percursos por uma série de salas que abrigam o acervo do Museu até chegar ao sino, de onde se tem uma ótima visualização de todo o centro da cidade. Ou seja, mais do que um edifício, a Catedral representa hoje um lugar passível de fruição em vários sentidos.

Um fato que ilustra bem esta questão foi a postura de restauração da Catedral, que se diferenciou das posturas adotadas em outros edifícios restaurados, ao conceber o processo como "obra aberta", ou seja, admitindo um convívio da população com as obras, permitindo a participação direta desta no zelo deste bem.

A construção do piso técnico, já mencionado, para o restauro do forro, permitiu que as atividades da Catedral continuassem normalmente, sendo que as entradas ao templo foram, de tempos em tempos modificadas, para a frontal ou as laterais, de acordo com as necessidades da obra, que só era interrompida no momento da missa.

Neste sentido, a proposta de reabilitação incluiu novas áreas do edifício para fruição do visitante, áreas anteriormente apenas visitadas por técnicos, tais como a sua cobertura, a torre dos sinos, os vãos entre o forro e o telhado; permitiu a observação dos ornamentos de madeira do forro a uma distância de dois metros, que abriram uma nova perspectiva de conhecimento e de pesquisa para os projetos de intervenção, implicando numa releitura do edifício, de suas circulações e o contato com a estrutura e os materiais tradicionais, presentes na construção. Isto, sem dúvida, só foi possível a partir da concepção e valorização da participação da população usuária em todo o processo de restauração e reabilitação.

O crescimento e o desenvolvimento da cidade, sem considerar seu patrimônio edificado, trouxe sérias conseqüências para os edifícios históricos, tornando-os cada 
vez mais isolados de seu próprio entorno. Este fato nos leva a refletir sobre a questão específica das áreas envoltórias, definidas para o raio de $300 \mathrm{~m}$ no entorno do edifício tombado, e que está prevista na legislação de patrimônio da cidade de Campinas. (13)

Esta legislação tem por intenção a proteção da moldura do bem tombado pela noção de monumento, compreendido na inscrição da Carta de Veneza, que diz ser o monumento inseparável do meio onde se encontra. A aplicação tardia da legislação em relação a este aspecto permitiu graves alterações de gabaritos e volumetrias nas zonas centrais, maior depositária de bens tombados. Hoje, o fato de que esta paisagem verticalizada já é algo consolidado nos leva a refletir sobre a conveniência e/ou eficiência de se manter uma restrição de altura no raio de $300 \mathrm{~m}$. O caso do edifício da Catedral é emblemático, neste sentido. Uma análise das futuras intervenções propostas a partir de critérios que possibilitem o diálogo com o edifício tombado em termos estéticos, e de funções compatíveis com a reabilitação da própria área central talvez seja mais importante do que uma restrição absoluta de gabarito em seu entorno.

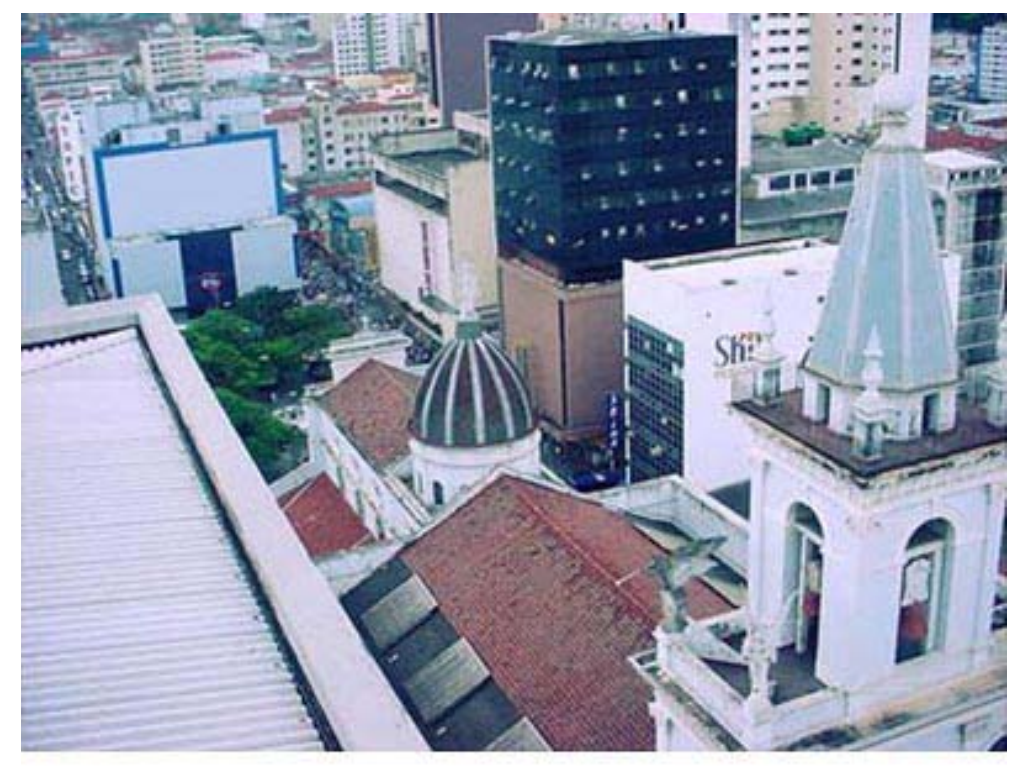

FIGURA 08 - Catedral vista de cima. Fotografia: Ana Carolina N. de P. Leite, Ejos S. Martins e Fernanda Batistella. Trabalho Final de Graduação, PUC-Campinas, 2003. 


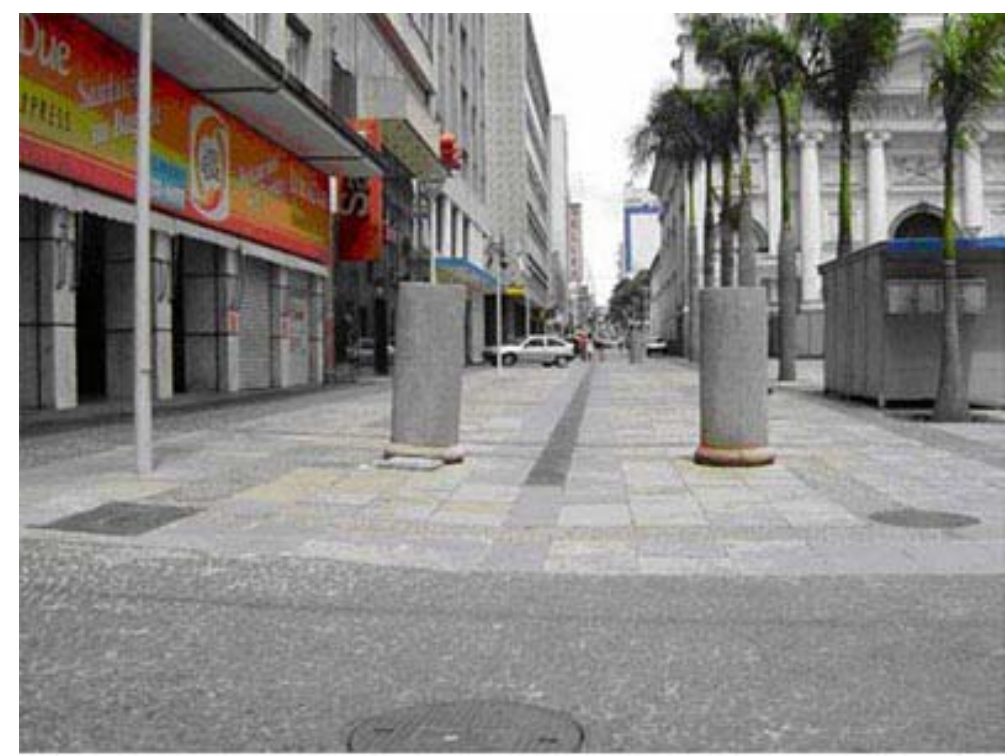

FIGURA 09 - Rua Costa Aguiar, à direita encontra-se a Catedral Gabarito elevado em seu entorno imediato. Fotografia: Paula Marques Braga.

Esta mudança de visão da relação do patrimônio edificado e a dinâmica da cidade (LEITE, R. P., 2004) afeta diretamente as decisões em relação à proteção da Catedral Metropolitana de Campinas, não apenas na questão funcional e física, mas também nas relações sociais que ela venha a estabelecer. A Catedral de Campinas, por ser um monumento de uso permanente e de localização estratégica no centro da cidade, exerce essa função de integrar o tecido urbano, aquele percorrido pelo pedestre, principalmente por estar localizada junto à Rua 13 de Maio, calçadão de comércio com intenso fluxo de pedestres, como já apontamos.

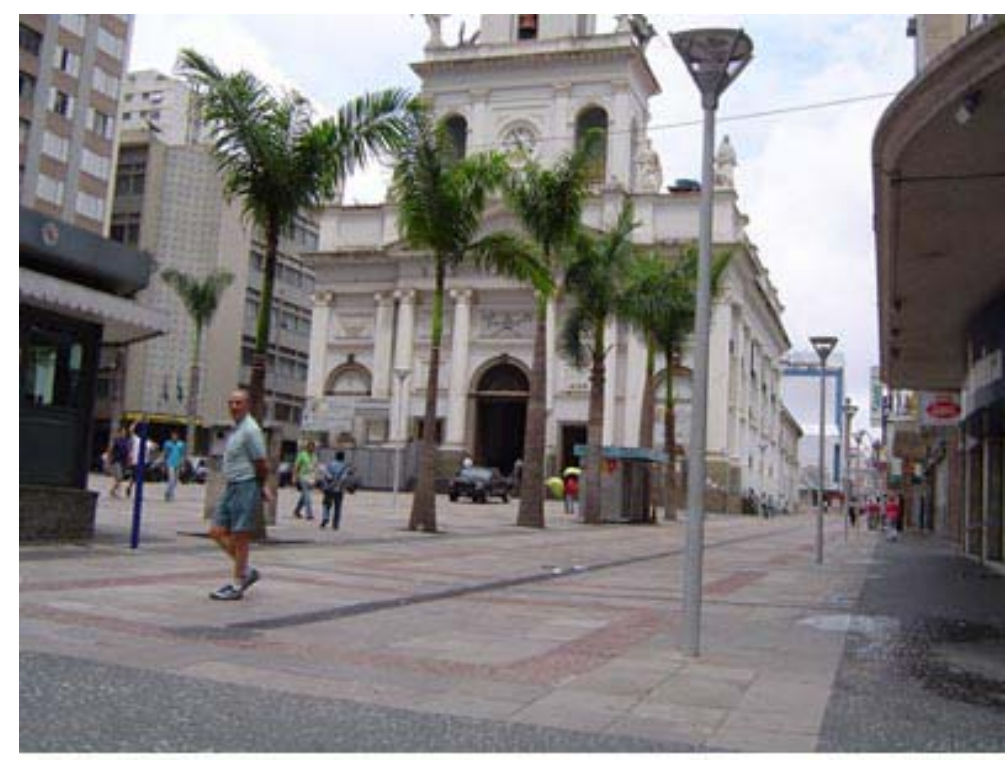

FIGURA 10 - Catedral vista a partir da Avenida Francisco Glicério. A padronização do piso e colocação da vegetação no Largo da Catedral dão maior amplitude à praça ao integrála visualmente com a Rua 13 de Maio. Fotografia: Paula Marques Braga. 
Em sua origem, as políticas de preservação têm por objetivo a afirmação de uma identidade coletiva, e a educação dos cidadãos quanto à importância da conservação de edifícios de interesse histórico e arquitetônico significativos. Para tanto, é fundamental a participação da sociedade, de diferentes grupos sociais, direta ou indiretamente, na apropriação desses bens. É importante que a decisão sobre o que é significativo para ser preservado tenha em conta mais do que os parâmetros técnicos ou históricos.

Este é o grande problema que se apresenta a partir da segunda metade do século $\mathrm{XX}$, a adequação desses edifícios tombados e preservados a uma cultura de massa, à busca da identificação. É esta questão, a da apropriação e uso do bem tombado, uma das linhas de reflexão a respeito do patrimônio de extrema importância quando se trata das implicações práticas do tombamento (FONSECA, 2005).

Na cidade de Campinas, edifícios como o Palácio dos Azulejos e o Palácio da Mogiana ilustram este problema. Exemplares arquitetônicos de um momento significativo da história da cidade, na época áurea do café e da expansão ferroviária, nos últimos vinte anos, passaram por uma sucessão de usos, nenhum deles capaz de reincorporá-los à dinâmica da cidade, deixando-os isolados e alheios ao cotidiano dos habitantes.

Por outro lado, no início das práticas de tombamento no Brasil, a grande maioria dos bens protegidos era de arquitetura religiosa. De acordo com Lúcio Costa, isso era provocado pelo profundo sentimento social que despertava. Segundo ele "A igreja, com aquele esplendor todo, estava aberta, pertencia a todos, qualquer pessoa do povo, por mais miserável que fosse era só entrar e ficar lá" (FONSECA, 2005, p. 108). A Catedral de Campinas não foge a esta regra, que parece ainda mais legítima hoje, quando o centro se encontra totalmente popularizado.

A não interdição do edifício durante a restauração, já incorporado ao cotidiano das pessoas, além de todos os aspectos já apontados, contribuiu como ação educativa natural ao despertar o interesse da população para a questão da preservação, e da importância de se manter o patrimônio edificado. Agregou mais esta vivência às memórias sobre o edifício. 
Monumento desde a sua construção, a Catedral apresenta significações distintas para o mesmo termo, em períodos diferentes de sua história. Foi construída para representar a riqueza e poder dos barões do café, numa época em que a cidade, ainda Vila de São Carlos, contava com cerca de quatro mil habitantes. Hoje, esta visão de monumento foi reconstruída pela sociedade, uma cidade popularizada, que a tem como imagem do próprio centro. Quem visita a área central de Campinas, passa pela Catedral Metropolitana. Visitada por cerca de três mil pessoas todos os dias, ali estão os fiéis que aguardam a missa, pedestres que param ali para descansar, e curiosos, atraídos pela sua grandiosidade.

Superado o seu papel como marco referencial na paisagem da cidade, em grande parte projetado em suas sucessivas fachadas, a Catedral pode recriar o seu "lugar" fundamental para a identidade da área central ao repropor a confluência entre seu espaço concreto e a rua. Seu edifício se coloca hoje como uma verdadeira arquitetura pública, dá continuidade aos espaços públicos do entorno, qualificando e individualizando estes logradouros urbanos.

\section{Notas}

(1) O Inventário da Área Central de Campinas está sendo realizado através de uma parceria entre a Prefeitura Municipal de Campinas e a Fapesp - Fundação de Amparo à Pesquisa do Estado de São Paulo.

(2) Condephaat: Conselho de Defesa do Patrimônio Histórico, Arqueológico, Artístico e Turístico do Estado de São Paulo.

(3) Condepacc: Conselho de Defesa do Patrimônio Artístico e Cultural de Campinas.

(4) As ações incluídas no projeto e seus custos em reais são: construção do Centro de Compras Popular (mais de 600 mil); criação da zeladoria do centro, Praça Imprensa Fluminense (mais de 1 milhão); Ceprocamp (mais de 4 milhões); nova rodoviária de Campinas, Vila Industrial, Estação Cultura (mais de 4 milhões); Palácio da Mogiana, recuperação de espaços públicos, Centro Cultural Evolução e outros equipamentos, Reurbanização da Rua 13 de Maio (mais de 5 milhões); Palácio dos Azulejos (quase 3 milhões). PREFEITURA Municipal de Campinas. Governo Democrático e Popular (Relatório Final de Gestão). Campinas, 2004.

(5) "A Catedral de Nossa Senhora da Conceição, Padroeira da cidade e da Diocese de Campinas", 1942. Monografia organizada por um paroquiano do respectivo Curato, como contribuição para o Congresso Eucarístico da Diocese. Oficinas Gráficas da "AVE MARIA". 
(6) Relatório realizado por Ramos de Azevedo quanto ao andamento das obras. O relatório descrevia, entre outros, a situação das alvenarias, revestimentos, carpintaria, escadas, cobertura e serralheria. "A Catedral de Nossa Senhora da Conceição, Padroeira da cidade e da Diocese de Campinas".

(7) Mapas do livro "Campinas século XX - 100 anos de história", Rede Anhanguera de Comunicação.

(8) Parecer favorável ao tombamento constante do processo enviado ao Condephaat.

(9) Site www.campinas.sp.gov.br/portal 2003 sites/noticias/projeto centro/pc.htm

(10) Os documentos referentes a esta atualização encontram-se no L"Habitat - Laboratório do Habitat, da FAU PUC- Campinas.

(11) Projeto Centro de Memória Catedral Metropolitana de Campinas. Estudo apresentado à Pro-Reitoria de Extensão e Assuntos Comunitários da PUC-Campinas, sob a coordenação da professora Maria Cristina Schicchi da FAU PUC-Campinas, em 2004.

(12) Projeto de restauro elaborado pelo curso de especialização da PUC-Campinas em Patrimônio Arquitetônico, Teoria e Projeto.

(13) Conselho de Defesa do Patrimônio Artístico e Cultural de Campinas - Condepacc.

\section{Referências Bibliográficas}

BADARÓ, Ricardo. Plano de Requalificação Urbana da área central de Campinas: [Versão preliminar]. Campinas: Prefeitura Municipal de Campinas, Secretaria de Planejamento, Desenvolvimento Urbano e Meio Ambiente - Deplan, mar. 2002.

BOITO, Camillo. Os restauradores. Tradução de Paulo Mugayar Kühl e Beatriz Mugayar Kühl. São Paulo: Ateliê Editorial, 2003.

A CATEDRAL de Nossa Senhora da Conceição, Padroeira da cidade e da Diocese de Campinas. Monografia organizada por um paroquiano do respectivo Curato, como contribuição para o Congresso Eucarístico da Diocese. Campinas: Oficinas Gráficas da "AVE MARIA", 1942.

FONSECA, Maria Cecília Londres. O patrimônio em processo: trajetória da política federal de preservação no Brasil. Rio de Janeiro: UFRJ, 2005.

IPHAN. Cartas patrimoniais. 3. ed. Brasília, DF, 1995.

LEITE, Ricardo. Catedral Metropolitana de Campinas: um templo e sua história. Campinas: Komedi, 2004. 
LEITE, Rogério Proença. Contra-usos da cidade. Lugares e espaço público na experiência urbana contemporânea. Campinas: Unicamp; Aracajú : UFS , 2004.

SESSO JÚNIOR, Geraldo. Retalhos da velha Campinas. Campinas: Palmeiras, 1970.

\section{Bibliografia Consultada}

\section{Livros}

BRANDI, Cesari. Teoria da restauração. Tradução de Beatriz Mugayar Kühl. São Paulo: Ateliê Editorial, 2004.

CHOAY, Françoise. A alegoria do patrimônio. São Paulo: Unesp, 2001.

PUPO, Celso Maria de Mello. Campinas, seu berço e juventude. Campinas, 1969. (Academia Campinense de Letras, n. 20)

SIMÃO, Maria Cristina Rocha. Preservação do Patrimônio Cultural em Cidades. Belo Horizonte: Autêntica, 2001.

VIOLLET-LE-DUC, Eugène Emmanuel. Restauração. Tradução de Beatriz Mugayar Kühl. São Paulo: Ateliê Editorial, 2000.

\section{Artigos de jornal}

CAMPINAS século XX. 100 anos de história. Correio Popular (Rede Anhanguera de Comunicação, Diário do Povo), 2000.

CATEDRAL é patrimônio há seis anos. Jornal Diário do Povo, 31 maio 1987.

IGREJAS retratam estilo do passado - É grande o valor arquitetônico das edificações religiosas, Jornal Correio Popular, 26 jun. 1988.

AUTORIA do projeto é desconhecida. Jornal Correio Popular, 8 dez. 1993.

PREFEITURA quer parceria para preservar Catedral. Jornal Correio Popular, 12 ago. 1997.

“EMPRESA doa R\$300 mil para início das obras. Jornal Correio Popular, 20 nov. 2003.

IGREJA é a maior do mundo em taipa. Jornal Correio Popular, 11 dez. 2003.

REFORMA limita área para fiéis e suspende casamentos. Jornal Correio Popular, 13 jan. 2004.

CATEDRAL de Campinas recebe doação de empresa: Companhia concedeu $\mathrm{R} \$ 50$ mil para restauro. Apesar da ajuda de fiéis e da iniciativa privada, campanha ainda necessita de R\$ 1,2 mi. Jornal Correio Popular, 27 maio 2004.

Sites

http://www.partes.com.br/igrejas/igreja de sao cristovao.htm 
http://cosmo.com.br/hotsites/campinas229anos/materias/mat05.shtm

http://www.citybrazil.com.br/sp/campinas/turismo.htm

http://www.unicamp.br/unicamp/canal aberto/clipping/marco2004/clipping040303 correiopop.html

http://www.amcham.com.br/update/update2004-08-20d dtml

http://eptv.globo.com/lazerecultura/3101200416301040.asp

http://www2.petrobras.com.br/CulturaEsporte/portugues/cultura/PatrimonioEdificado/CatedralCampinas.htm

http://www.campinas.sp.gov.br/portal 2003 sites/noticias/projeto centro/pc catedral.htm

http://www.cpopular.com.br/metropole/conteudo/mostra noticia.asp?noticia=1316765\&area=2230\&authent=4065 $\underline{46372767424157470526554373}$

http://www.novomilenio.inf.br/real/ed126n.htm

http://www.colorfotos.com.br/sp/catedral.htm

http://www.sampa.art.br/SAOPAULO/Catedral\%20da\%20S\%C3\%A9.htm

http://www1.folha.uol.com.br/folha/cotidiano/ult95u59892.shtml

http://www1.folha.uol.com.br/folha/especial/2002/catedraldase/a construcao do simbolo.shtml

http://www1.folha.uol.com.br/folha/especial/2002/catedraldase/a reforma da catedral.shtml

http://www1.folha.uol.com.br/folha/especial/2002/catedraldase/raio x da reforma.shtm

http://www1.folha.uol.com.br/folha/cotidiano/ult95u59969.shtml

http://www.vitruvius.com.br/institucional/inst47/inst47.asp

http://www.abril.com.br/especial450/materias/catedral/

http://www.abril.com.br/especial450/materias/catedral/texto1.html

http://www.abril.com.br/especial450/materias/catedral/texto2.html

\section{Arquivos}

Centro de Memória da Unicamp

Conselho de Defesa do Patrimônio Artístico e Cultural de Campinas

Arquivo Fotográfico da Rede Anhanguera de Comunicação

Revista CPC, São Paulo, n. 3, p. 33-53, nov. 2006/abr. 2007 
Catedral Metropolitana de Campinas

Cúria Metropolitana

* Arquiteta e Urbanista.

** Docente da Pontifícia Universidade Católica de Campinas.

Este artigo foi escrito baseado na pesquisa de Iniciação Científica de Paula Marques Braga, financiada pela Fundação de Amparo à Pesquisa do Estado de São Paulo (FAPESP) e orientada pela Profa. Dra. Maria Cristina Schicchi. 